\title{
Suitability of target region amplified polymorphism (TRAP) markers to discern genetic variability in sweet sorghum
}

\author{
Yehia A. Khidr ${ }^{1 *}$ (D), Sileshi A. Mekuriaw ${ }^{1,2}$, Adel E. Hegazy ${ }^{1}$ and Enass Amer ${ }^{1}$
}

\begin{abstract}
Background: Sweet sorghum is an emerging biofuel candidate crop with multiple benefits as a source of biomass energy. Increase of biomass and sugar productivity and quality is a central goal in its improvement. Target region amplified polymorphism (TRAP) is a polymerase chain reaction (PCR) based functional marker system that can detect genetic diversity in the functional region of target genes. Thirty sweet sorghum genotypes were used to study the potential of 24 pairs of TRAP marker system in assessing genetic diversity with regard to three lignin and three sucrose biosynthesis genes.

Results: A total of 1638 bands were produced out of which 1161 (70.88\%) were polymorphic at least at one locus. The average polymorphic information content (PIC), resolving power (RP), marker index (MI), Shannon's diversity index $(H)$, and gene diversity values were $0.32,8.86,1.74,3.25$, and 0.329 , respectively. Analysis of molecular variance (AMOVA) revealed a highly significant genetic variation both within and among accessions studied $(P=0.01)$. However, the variation within the population was higher than among the populations (accessions). Bootstrap analysis showed that the number of loci amplified using this marker system is sufficient to estimate the available genetic diversity. The thirty genotypes were categorized into five clusters using a similarity matrix at 0.72 coefficient of similarity. The genotypes were also grouped mostly according to their geographic origin where the Ethiopian and Egyptian genotypes tend to fall in specific clusters. Moreover, the genotypes reflected the same pattern of distribution when ordinated using principal coordinate analysis.
\end{abstract}

Conclusions: In conclusion, TRAP marker can be used as a powerful tool to study genetic diversity in sweet sorghum.

Keywords: Lignin, Sucrose, Molecular markers

\section{Background}

Sweet sorghum (Sorghum bicolor L. Moench) is a member of the family Poaceae and genus Sorghum $(2 n=20)$. The genus Sorghum encompasses three species: Sorghum bicolor, Sorghum propinquum, and Sorghum halepense. The species S. bicolor includes three subspecies: S. bicolor subsp. bicolor, S. bicolor subsp. drummondii, and S. bicolor subsp. verticilliflorum [1]. Sweet sorghum is a variety of

\footnotetext{
* Correspondence: yehia.khidr@gebri.usc.edu.eg

'Department of Plant Biotechnology, Genetic Engineering and

Biotechnology Research Institute, University of Sadat City, Sadat City, Egypt Full list of author information is available at the end of the article
}

sorghum known for its long, sweet, and juicy stalk. Due to its high biomass production and sugar accumulation potential under low input conditions and unique stress tolerance capability, it appears as an important candidate bioenergy crop $[2,3]$. It has a potential to produce as much as $13.2 \mathrm{t} / \mathrm{ha}$ of total sugars that is equivalent to 8000 ( $1 /$ ha)/year of ethanol depending on the genotype, environment, and input conditions [4].

Global energy consumption is predicted to rise nearly by $50 \%$ between 2018 and 2050 according to the US energy administration (www.eia.gov/ieo). On the other hand, depletion of fossil resources, global warming due to the 
increase in atmospheric carbon load and soaring oil prices are posing eminent challenges on the global economy and environmental safety [5]. Biofuels such as ethanol produced from plant biomass with lower food-feed tradeoffs and input requirements are among the alternatives to avert this challenge.

Lignocellulosic biomass obtained from agricultural waste and grass species like sweet sorghum is a promising source of nonfood-based biofuel feedstocks. Lignin is a complex phenylpropanoid polymer that binds the cell walls of supporting and conductive tissues, such as fibers and tracheary elements hindering the efficient bioconversion of structural sugars into ethanol requiring a harsh rate-limiting pretreatment procedure [6-8].

Lowering lignin content and enhancing sugar accumulation potential are the main breeding objectives for the improvement of the crop [9, 10]. Decreasing of the recalcitrance of biomass for fermentation can be achieved through downregulation of enzymes in the monolignol biosynthetic pathway [11-13]. This calls for a targeted breeding effort to optimize biomass yield and quality. Understanding the degree and pattern of genetic diversity existing in the available germplasm resources is a key step in the breeding process geared toward addressing the gap.

An array of marker systems, including randomly amplified polymorphic DNA (RAPD) [14, 15], amplified fragment length polymorphism (AFLP) [16, 17], inter simple sequence repeats (ISSR) [15], simple sequence repeats (SSR) [17-21], and single nucleotide polymorphisms (SNP) $[18,22]$ markers have been used to study patterns of genetic diversity and relationship among sweet sorghum accessions and breeding lines. Markers that are designed to measure genetic diversity for target-specific breeding purposes should be based on functionally characterized genes since they may reflect functional polymorphisms [23]. Unlike conventional random markers such as RAPD, restriction fragment length polymorphism (RFLP), AFLP, and SSR functional diversity markers that are physically associated with coding regions of the genome are developed by designing primers from annotated expressed sequence tag (EST) sequences of specific gene [23, 24].

Target region amplification polymorphism (TRAP) is a polymerase chain reaction (PCR) based marker system involving a fixed primer designed from EST sequence data of a target gene combined with an arbitrary primer having an AT- or CG-rich core sequenc e[25]. It is a multi-locus marker that can potentially be exploited for genotyping and tagging candidate genes controlling a trait of interest. These markers are characterized by their simplicity, high yield, reproducibility, and can be sequenced [26]. TRAP marker systems are used to study genetic diversity in different crop species such as castor bean [27], guarana [28], lettuce [29], mango [30], salvia [31], sugarcane [32, 33], sunflower [34], and wheat [35].
A variety of marker attributes including the percentage of polymorphic bands (PPB), polymorphic information content (PIC), Shannon diversity index $(\mathrm{H})$, resolving power (RP), and marker index (MI) are used to estimate the overall efficiency of the marker system. The PIC of a marker evaluates the discriminatory capability of a marker system among genotypes based on their pattern of polymorphism using the frequency and distribution of the alleles in a locus. The MI and RP of a marker are used to estimate the efficiency of a marker system to characterize a larger set of germplasm resources [36]. To the best of our knowledge, there is no report on the utilization of TRAP marker system on sweet sorghum as a functional marker targeting important traits of interest. This study is designed to evaluate the efficiency of TRAP markers based on three lignin pathway and three sucrose metabolism genes to study genetic variability and relatedness among sweet sorghum genotypes.

\section{Methods \\ Plant material}

A panel of 30 sweet sorghum materials comprising seventeen landrace collections and three cultivars from Ethiopia and thirteen elite cultivars obtained from the sugar crops research institute, Agriculture Research Center, Egypt, were planted in pots for genomic DNA extraction for about 15 days (Table 1). The Ethiopian landrace collections with their passport data were obtained from the Ethiopian Biodiversity Institute (EBI), Addis Ababa, Ethiopia.

\section{DNA extraction}

Genomic DNA was extracted from fresh young leaves of 15 days old sweet sorghum seedlings digested in liquid nitrogen using Thermo Scientific GeneJET Plant Genomic Extraction mini kit according to the manufacturers protocol. The DNA concentrations and quality were determined using Thermo Scientific ${ }^{\mathrm{Tm}}$ NanoDrop $^{\mathrm{Tm}} 2000$ spectrophotometer. All the DNA samples were adjusted to a concentration of $10 \mathrm{ng} / \mu \mathrm{L}$ using Thermo Scientific nuclease-free water for PCR amplification.

\section{Primer design}

A total of twenty-four primer combinations comprising six specific and four arbitrary primers were used in this study (Table 2). The gene-specific (fixed) primers were designed from the sorghum expressed sequence tags (ESTs) database from the NCBI (https://www.ncbi.nlm.nih.gov/ gene). Primer3 software tool (http://www.bioinformatics. $\mathrm{nl} /$ cgi-bin/primer3plus/primer3plus.cgi) was used by setting maximum and minimum size set to 18 and 20 base pairs and the optimum, maximum, and minimum $\mathrm{Tm}$ were set to $53^{\circ} \mathrm{C}, 55^{\circ} \mathrm{C}$, and $50^{\circ} \mathrm{C}$, respectively. Four arbitrary primers that comprised three selective nucleotides at 
Table 1 List and source of 30 sweet sorghum genotypes used in the study

\begin{tabular}{|c|c|c|c|c|c|c|c|}
\hline No. & Accession & Type & Source & No. & Accession/cultivar & Type & Source \\
\hline 1 & acct1_1SW & Land race & Ethiopia & 16 & acct39_1 ST & Land race & Ethiopia \\
\hline 2 & acct31sw & Land race & Ethiopia & 17 & acct24_1ST & Land race & Ethiopia \\
\hline 3 & acct6_1 SW & Land race & Ethiopia & 18 & Mn1383 & Cultivar & Egypt \\
\hline 4 & acct264 ST & Land race & Ethiopia & 19 & Ramada & Cultivar & Egypt \\
\hline 5 & acct221 ST & Land race & Ethiopia & 20 & GKGaba & Cultivar & Egypt \\
\hline 6 & acct133 SW & Land race & Ethiopia & 21 & Mn1500 & Cultivar & Egypt \\
\hline 7 & acct133_1 SW & Land race & Ethiopia & 22 & Umbrella & Cultivar & Egypt \\
\hline 8 & $\operatorname{acct301ST}$ & Land race & Ethiopia & 23 & Honey & Cultivar & Egypt \\
\hline 9 & acct1_1SW & Land race & Ethiopia & 24 & Brandes & Cultivar & Egypt \\
\hline 10 & acct32 SW & Land race & Ethiopia & 25 & Eg-b & Cultivar & Egypt \\
\hline 11 & acct41 SW & Land race & Ethiopia & 26 & Eg-a & Cultivar & Egypt \\
\hline 12 & acct10_1 NW & Land race & Ethiopia & 27 & $\mathrm{Eg}-\mathrm{C}$ & Cultivar & Egypt \\
\hline 13 & acct38_1 ST & Land race & Ethiopia & 28 & A-2267-2 & Cultivar & Ethiopia \\
\hline 14 & acct31sw & Land race & Ethiopia & 29 & NGTJ-2 & Cultivar & Ethiopia \\
\hline 15 & acct12_2NW & Land race & Ethiopia & 30 & Karmifma & Cultivar & Ethiopia \\
\hline
\end{tabular}

the 3 '-end, $4 \mathrm{AT} / \mathrm{GC}$ rich sequences targeting intronexon regions, respectively, and 11 random (filler) sequences at the $5^{\prime}$-end [37].

\section{PCR amplification}

PCR amplification was conducted with a final reaction volume of $15 \mu \mathrm{L}$ : 7.5 master mix (COSMO PCR RED) manufactured by Willowfort, UK, $3.5 \mu \mathrm{L}$ (35 ng) of template DNA, $0.5 \mu \mathrm{L}$ of forward and reverse primers $(10 \mathrm{mM}$ each), and $3 \mu \mathrm{L}$ nuclease-free water. The PCR was carried out with an initial denaturation at $94{ }^{\circ} \mathrm{C}$ for $5 \mathrm{~min}$ and $94^{\circ} \mathrm{C}$ for $45 \mathrm{~s}$; annealing at $35^{\circ} \mathrm{C}$ for $45 \mathrm{~s}$ and extension at $72^{\circ} \mathrm{C}$ for $1 \mathrm{~min}$, for the first 5 cycles followed by 35 cycles with annealing temperatures ranging from $50-55^{\circ} \mathrm{C}$ depending on the primer $\mathrm{Tm}$ and a final extension step at $72{ }^{\circ} \mathrm{C}$ for $7 \mathrm{~min}$ using Techne TC-4000 Thermal Cycler. The PCR products were resolved using $1.5 \%$ agarose gel in a $0.5 \mathrm{X}$ Tris borateEDTA (TBE) as a running buffer and stained with ethidium bromide $(0.5 \mu \mathrm{g} / \mathrm{mL})$. The size of the fragments was estimated by visual comparison with a 50-bp DNA ladder (Thermo Scientific). The gel was photographed under UV light using a Bio-Rad gel imaging system.

\section{Data analysis}

The bands were scored manually for each test genotype as presence (1) or absence (0) in a binary data matrix. Only clear and unambiguous bands were scored. The degree of informativeness of the TRAP marker combinations was assessed by analyzing the banding pattern produced by each primer measured in terms of the total number of bands $(\mathrm{T})$, number of polymorphic bands (PL), and their proportion (\%P). The suitability of the marker to study the genetic variability of the sweet sorghum genotypes was evaluated by calculating five marker attributes namely polymorphic information content (PIC), resolving power (RP),

Table 2 Fixed and arbitrary primers used as TRAP markers

\begin{tabular}{|c|c|c|c|c|}
\hline & Gene/primer name & Gene ID/accession & Nucleotide sequence $\left(5^{\prime}>3^{\prime}\right)$ & Tm \\
\hline \multirow[t]{3}{*}{ Lignin-related genes } & Cinnamoyl coA reductase (CCR) & LOC8054741 & GTCAGGAACCCAGATGAC & 55 \\
\hline & Cinnamoyl alcohol dehydrogenase (CAD) & LOC110434683 & GGGCTTCAAAGTACCCTA & 54 \\
\hline & Caffeic acid 3-O-methyltransferase (COMT) & LOC8070884 & CAAGAAGCTCCTCGAGTT & 54 \\
\hline \multirow[t]{3}{*}{ Sucrose-related genes } & Sucrose synthase (susy) & Sb01g033060 & ATGGTATTCTCCGCAAGTGG & 58 \\
\hline & Soluble acid invertase (Inv) & Sb04g000620 & CATCGTTGCAGGGTATCCC & 59 \\
\hline & Sucrose phosphate synthase (sps) & Sb05g007310 & GCAAACCTTACGCTGATACTG & 56 \\
\hline \multirow[t]{4}{*}{ Arbitrary primer } & $E m_{1}$ & & GACTGCGTACGAATTTGC & 49 \\
\hline & $\mathrm{Em}_{2}$ & & GACTGCGTACGAATTGAC & 53 \\
\hline & $\mathrm{Em}_{3}$ & & GACTGCGTACGAATTTGA & 53 \\
\hline & $\mathrm{Em}_{4}$ & & GACTGCGTACGAATTAAT & 52 \\
\hline
\end{tabular}


effective multiplex ratio (EMR), marker index (MI), and Shannon diversity index $(\mathrm{H})$ for each marker combination and averaged for all the marker combinations. The PIC was computed using allele frequencies generated as a ratio of amplified fragments to the total number of genotypes as $P I C=2 f_{i}\left(1-f_{i}\right)$ where "fi" is the frequency an amplified allele " $\mathrm{i}$ " while $\left(1-f_{i}\right)$ is the frequency of the null allele [37]. The marker index was computed as the product of effective multiplex ratio (EMR) and diversity index (DI), where EMR refers to the number of polymorphic markers generated per assay and the DI is the average PIC value [38]. The RP indicates the ability of the markers to distinguish between accessions [36] for each primer combinations was computed as: $R P=\sum I b$, where "Ib" is the band in formativeness that takes the values of $1-\left[2 \times\left|0.5-P_{i}\right|\right]$, where " $P_{i}$ " is the proportion of each genotype containing the band [39]. The diversity index, which indicates the genetic diversity of the germplasm, was calculated using the formula $D I=1-1 / L \sum P_{i}^{2}$ in which " $P_{i}$ " is the allele frequency (each individual allele was considered unique) and "L" is the number of loci. Shannon's diversity index $(\mathrm{H})$ was computed using the formula: $H=-\sum f_{i} \ln$ $f_{i}$ where "fi" is the frequency of an amplified for a marker band relative to all bands amplified across all the genotypes. The expected heterozygosity or gene diversity that refers to the probability that two randomly chosen alleles from the population are different and was computed using the PowerMarker V3.0 software [40]. Pairwise Nei's unbiased genetic distance was calculated and the resulting matrix was used for cluster analysis. Cluster analysis was performed using the unweighted pair group method with arithmetic mean (UPGMA) and a phylogenetic tree was constructed using the NTSYS-pc 2.10 software [41]. Bootstrap analysis was performed to determine the number of loci enough to effectively estimate the genetic diversity existing among the genotypes using the GENES software [42]. The pairwise genetic distance matrix utilized above for cluster analysis was used for the analysis. A simulated matrix was established by resampling using 50 to 1000 numbers of loci with 10,000 permutations. The simulated distance matrices were then correlated with the actual distance matrix and verified using Kruskal stress value [43]. The number of loci that can sufficiently estimate the genetic diversity in a set of genotypes corresponds to a value where the Kruskal stress value $(E)$ less than 0.05 and the correlation coefficient $(r)$ approaches the maximum value (1). The underlying genetic relationships among the 30 sweet sorghum genotypes were further analyzed using DARwin ${ }^{\circ}$ software version (6.0.21) which is based on distance multivariate exploratory analysis (dissimilarity matrix). The analysis of molecular variance (AMOVA) was computed to determine the proportions of the molecular variance between and within groups of accessions (GenAlex 6 in Microsoft Excel).

\section{Results}

A total of 1638 bands were amplified from the 30 sweet sorghum genotypes using 24-marker combinations. Out of these bands, 1161 (70.88\%) were polymorphic at least at one of the loci. The number of fragments generated per primer pair ranged from 36 (SUSy/Em03) to 108 (COMT/Em01) with a mean of 68.25 bands per primer combination (Fig. 1). A relatively higher number of bands were amplified using the lignin-based markers (927) with $71.18 \%$ polymorphism as compared to markers based on sucrose metabolism genes (711) with $69.62 \%$ polymorphism.

The maximum percentage of polymorphic loci was $87.5 \%$ (CCR/Em04) while the minimum percent polymorphism $55.56 \%$ (CAD/Em02). The percent polymorphism for

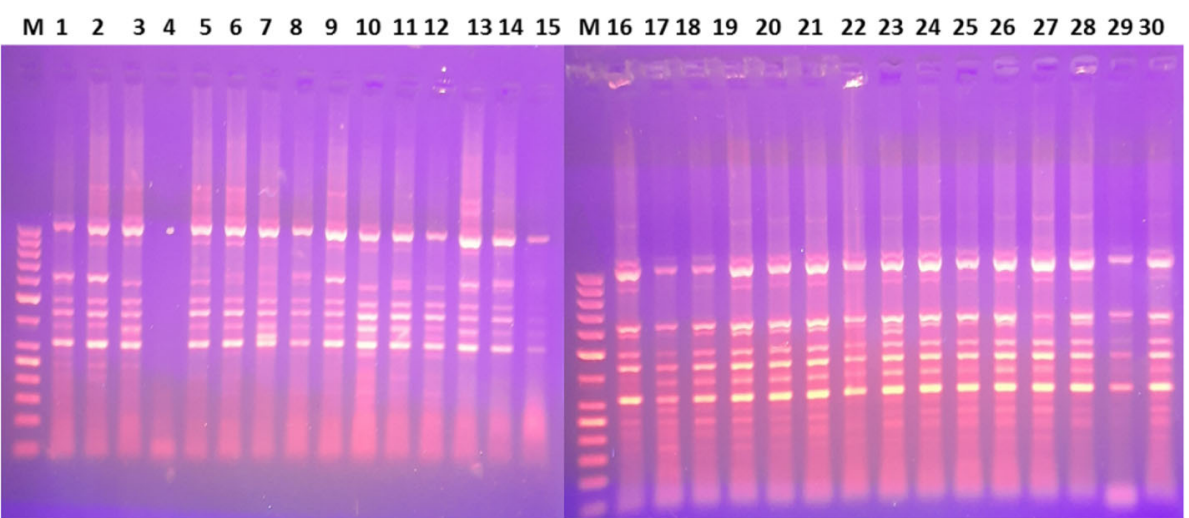

Fig. 1 TRAP profiling of thirty sweet sorghum genotypes amplified with COMT/Em2 primer combination in a 1.5\% Agarose gel compared with a 50 bp lane 
markers based on lignin related genes ranged between 55.56 and $87.5 \%$, while the range for their sucrose-based counterparts was 60 to $80 \%$ (Table 3). The polymorphic information content (PIC) computed as a mean over all the genotypes ranged from 0.22 (SPS/EM04) to 0.45 (SPS/ EM01) for sucrose related markers and 0.18 (CCR/EM04) to $0.42(\mathrm{CCR} / \mathrm{EM} 03)$ for lignin related markers (Table 4). The overall average PIC displayed by all marker combinations was 0.32 that showed moderate to higher informativeness of the marker. Both groups of TRAP marker systems designed based on sucrose and lignin related genes showed almost similar PIC value (0.32 and 0.33), respectively.
The resolving power of the markers ranged from 5.40 (CAD/EM03) to 17.80 (COMT/EM01) for markers based on lignin-related genes while it ranged from 4.80 (SUSy/EM03) to 10.93 (SuSy/Em3 and COMT/Em1) for markers based on sucrose metabolism genes. The mean resolving power was 8.86 for all markers tested over the genotypes. However, lignin-based markers showed a relatively higher RP (9.97) as compared to sucroserelated markers (7.74). The marker with a higher RP (COMT/Em1) had a higher capability to distinguish among the genotypes. The marker index ranged from 0.69 (SUSy/EM04) to 3.10 (COMT/EM1) with a mean

Table 3 Polymorphism of 24 TRAP marker combinations on 30 sweet sorghum genotypes

\begin{tabular}{|c|c|c|c|c|c|}
\hline \multirow[t]{2}{*}{ Gene function } & \multicolumn{2}{|l|}{ Primer (marker) combinations } & \multirow{2}{*}{$\begin{array}{l}\text { Total } \\
\text { number } \\
\text { of } \\
\text { bands }\end{array}$} & \multirow{2}{*}{$\begin{array}{l}\text { Number of } \\
\text { polymorphic } \\
\text { bands }\end{array}$} & \multirow{2}{*}{$\begin{array}{l}\text { Polymorphi } \\
\text { bands (\%) }\end{array}$} \\
\hline & Forward (fixed) & Reverse (arbitrary) & & & \\
\hline \multirow[t]{12}{*}{ Lignin biosynthesis } & Cinnamoyl coA reductase (CCR) & Em01 & 54 & 36 & 66.67 \\
\hline & & Em02 & 63 & 36 & 57.14 \\
\hline & & Em03 & 63 & 45 & 71.43 \\
\hline & & Em04 & 72 & 63 & 87.50 \\
\hline & Cinnamoyl alcohol dehydrogenase (CAD) & Em01 & 90 & 63 & 70.00 \\
\hline & & Em02 & 81 & 45 & 55.56 \\
\hline & & Em03 & 63 & 36 & 57.14 \\
\hline & & Em04 & 63 & 36 & 57.14 \\
\hline & Caffeic acid 3-O-methyltransferase (COMT) & Em01 & 108 & 90 & 83.33 \\
\hline & & $\mathrm{Em02}$ & 99 & 81 & 81.82 \\
\hline & & Em03 & 81 & 63 & 77.78 \\
\hline & & Em04 & 90 & 72 & 80.00 \\
\hline Total & & & 927 & 666 & \\
\hline Mean & & & 142.62 & 102.46 & 70.46 \\
\hline \multirow[t]{12}{*}{ Sucrose biosynthesis } & Sucrose synthase (SUSy) & Em01 & 45 & 36 & 80.00 \\
\hline & & Em02 & 54 & 36 & 66.67 \\
\hline & & Em03 & 36 & 27 & 75.00 \\
\hline & & Em04 & 45 & 27 & 60.00 \\
\hline & Sucrose phosphate synthase (SPS) & Em01 & 72 & 54 & 75.00 \\
\hline & & $\mathrm{Em02}$ & 90 & 54 & 60.00 \\
\hline & & Em03 & 45 & 27 & 60.00 \\
\hline & & Em04 & 63 & 45 & 71.43 \\
\hline & Soluble acid invertase (Inv) & Em01 & 72 & 54 & 75.00 \\
\hline & & Em02 & 54 & 36 & 66.67 \\
\hline & & Em03 & 81 & 63 & 77.78 \\
\hline & & Em04 & 54 & 36 & 66.67 \\
\hline Total & & & 711 & 495 & \\
\hline Mean & & & 59.25 & 41.25 & 69.52 \\
\hline Grand total & & & 1638 & 1161 & \\
\hline Grand mean & & & 68.25 & 48.38 & 70.88 \\
\hline
\end{tabular}

$T$ total number of loci; $P L$ polymorphic loci; $P \%$ polymorphism percentage 
Table 4 TRAP marker attributes and diversity indices of 30 sweet sorghum genotypes

\begin{tabular}{|c|c|c|c|c|c|c|c|}
\hline \multirow[t]{2}{*}{ Gene function } & \multicolumn{2}{|l|}{ Primer (marker) combinations } & \multirow[t]{2}{*}{ PIC } & \multirow[t]{2}{*}{$\mathrm{RP}$} & \multirow[t]{2}{*}{ MI } & \multirow[t]{2}{*}{$\mathrm{H}$} & \multirow[t]{2}{*}{ G D } \\
\hline & Forward (fixed) & Reverse (arbitrary) & & & & & \\
\hline \multirow[t]{12}{*}{ Lignin biosynthesis } & \multirow[t]{4}{*}{ Cinnamoyl coA reductase (CCR) } & Em01 & 0.24 & 6.53 & 0.96 & 3.38 & 0.214 \\
\hline & & $\mathrm{Em02}$ & 0.29 & 6.87 & 1.16 & 3.34 & 0.344 \\
\hline & & Em03 & 0.42 & 8.13 & 2.10 & 3.17 & 0.281 \\
\hline & & Em04 & 0.18 & 10.67 & 1.26 & 3.37 & 0.202 \\
\hline & \multirow[t]{4}{*}{ Cinnamoyl alcohol dehydrogenase (CAD) } & Em01 & 0.37 & 12.27 & 2.59 & 3.19 & 0.415 \\
\hline & & $\mathrm{Em02}$ & 0.38 & 7.27 & 1.90 & 3.38 & 0.343 \\
\hline & & Em03 & 0.39 & 5.40 & 1.56 & 3.28 & 0.340 \\
\hline & & Em04 & 0.35 & 6.27 & 1.40 & 3.27 & 0.374 \\
\hline & \multirow[t]{4}{*}{ Caffeic acid 3-O-methyltransferase (COMT) } & Em01 & 0.31 & 17.80 & 3.10 & 3.37 & 0.317 \\
\hline & & Em02 & 0.23 & 13.73 & 2.07 & 3.36 & 0.200 \\
\hline & & Em03 & 0.41 & 10.53 & 2.87 & 3.28 & 0.393 \\
\hline & & Em04 & 0.37 & 14.20 & 2.96 & 3.10 & 0.324 \\
\hline Mean & & & 0.33 & 9.97 & 1.99 & 3.29 & 0.374 \\
\hline \multirow[t]{12}{*}{ Sucrose Biosynthesis } & \multirow[t]{4}{*}{ Sucrose synthase (SUSy) } & Em01 & 0.27 & 6.53 & 1.08 & 3.10 & 0.368 \\
\hline & & Em02 & 0.27 & 6.67 & 1.08 & 3.28 & 0.290 \\
\hline & & Em03 & 0.29 & 4.80 & 0.87 & 3.37 & 0.381 \\
\hline & & Em04 & 0.23 & 5.27 & 0.69 & 3.37 & 0.233 \\
\hline & \multirow[t]{4}{*}{ Sucrose phosphate synthase (SPS) } & Em01 & 0.45 & 9.93 & 2.70 & 2.15 & 0.397 \\
\hline & & Em02 & 0.39 & 9.73 & 2.34 & 3.31 & 0.322 \\
\hline & & Em03 & 0.33 & 5.40 & 0.99 & 3.39 & 0.481 \\
\hline & & Em04 & 0.22 & 9.07 & 1.10 & 3.34 & 0.258 \\
\hline & \multirow[t]{4}{*}{ Soluble acid invertase (Inv) } & Em01 & 0.32 & 10.93 & 1.92 & 3.30 & 0.248 \\
\hline & & Em02 & 0.37 & 6.93 & 1.48 & 3.29 & 0.409 \\
\hline & & Em03 & 0.33 & 10.93 & 2.31 & 3.30 & 0.402 \\
\hline & & Em04 & 0.32 & 6.73 & 1.28 & 3.38 & 0.357 \\
\hline Mean & & & 0.32 & 7.74 & 1.49 & 3.22 & 0.345 \\
\hline Grand mean & & & 0.32 & 8.86 & 1.74 & 3.25 & 0.329 \\
\hline
\end{tabular}

PIC Polymorphic information content; RP Resolving power; MI Marker index; $H$ Shannon diversity index, GD Gene diversity (expected heterozygosity)

value of 1.74. The lignin-based markers displayed a higher mean marker index (1.99) than their sucrosebased counterparts (1.49).

\section{Genetic diversity}

The mean Shannon's diversity index of genotypes with respect to the 24 marker combinations was 3.25 , indicating a significant genetic variability among the genotypes using this marker system. The lignin and sucrose gene-based markers gave a comparable value (3.29 and 3.22), respectively. The average gene diversity detected using the 24 TRAP markers was 0.329 . The gene diversity detected among genotypes using lignin-based markers was higher (0.379) than the value obtained using markers designed for sucrose genes (0.345) (Table 4). Analysis of molecular variance (AMOVA) revealed a highly significant genetic variation both within and among studied accessions $(P=0.01)$. However, the total variation was $79.02 \%$ within the accessions while the remaining was $20.98 \%$ among the accession (Table 5).

\section{Bootstrap analysis}

Bootstrap analysis was conducted by setting a series of values for the number of loci in each resampling cycle. When the number of loci used for resampling increased, it was observed that the correlation coefficient between the simulated and original distance matrices increased while the Kruskal stress value decreased (Fig. 4). When resampling was performed with 401 loci the correlation coefficient value was 0.86 which is closer to its maximum value (1) and the stress value reached 0.035. A stress value lower than 0.05 is acceptable to estimate the number of loci sufficient to assess genetic diversity [42]. However, in the 
Table 5 AMOVA for 30 sweet sorghum accessions using 24 TRAP marker combinations

\begin{tabular}{llllll}
\hline Source & df & SS* & Est. var. & \%D & P value* \\
\hline Among accessions & 29 & 121.712 & 3.24 & $79.02($ Fst $=0.724)$ \\
Within accessions & 690 & 23.222 & 0.86 & 20.98 \\
Total & 719 & 144.934 & 4.10 & \\
\hline
\end{tabular}

df Degrees of freedom, SS Sum of square, Est.var. Estimated variance, \%D Distribution of total variance

present study, we have a total of 1638 loci that is by far higher than the number of loci required to estimate the genetic diversity among the test genotypes.

\section{Cluster analysis}

Cluster analysis performed on the thirty sweet sorghum genotypes based on similarity matrix using the unweighted pair group method with arithmetic mean (UPGMA). The genotypes were discriminated into five clusters at 0.72 coefficient of similarity (Fig. 2). Cluster I comprised two genotypes that were obtained from the same locality while cluster II and cluster III were the larger clusters, each of them containing thirteen genotypes. Clusters IV and V were found to contain one genotype each that is distinctly different from all the other genotypes. The second cluster comprised of genotypes entirely of Ethiopian origin collected in the adjoining areas indicated by the letters at the end of each genotype. All the Egyptian cultivars were found to fall in the third cluster except two Ethiopian genotypes indicating the evolutionary relatedness existing among the genotypes.

\section{Principal coordinate analysis}

The principal coordinate analysis based on the dissimilarity matrix ordinated the genotypes into distinct classes. The pattern of the distribution of the genotypes was quite similar to the finding in the cluster analysis (Fig. 3). The three principal coordinate axes (eigenvalue > 1) were found to explain $73.97 \%$ of the total variation existing among the 30 sweet sorghum genotypes.

\section{Discussion}

This study evaluated the efficiency and informativeness of TRAP markers designed using two important biofuel related gene sequences (lignin and sucrose) to investigate the genetic diversity of germplasm

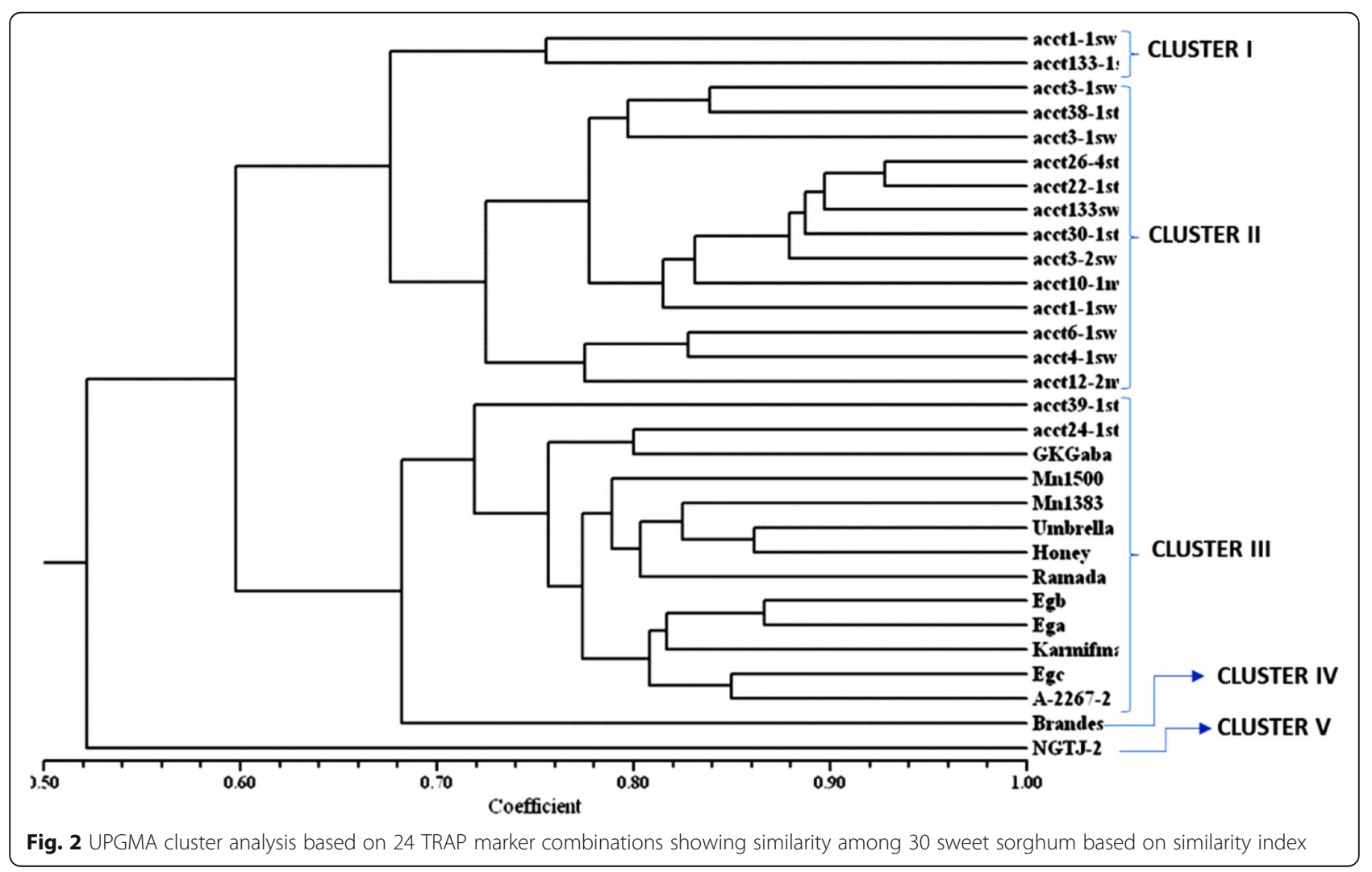




\section{Factorial analysis: (Axes 1/2)}

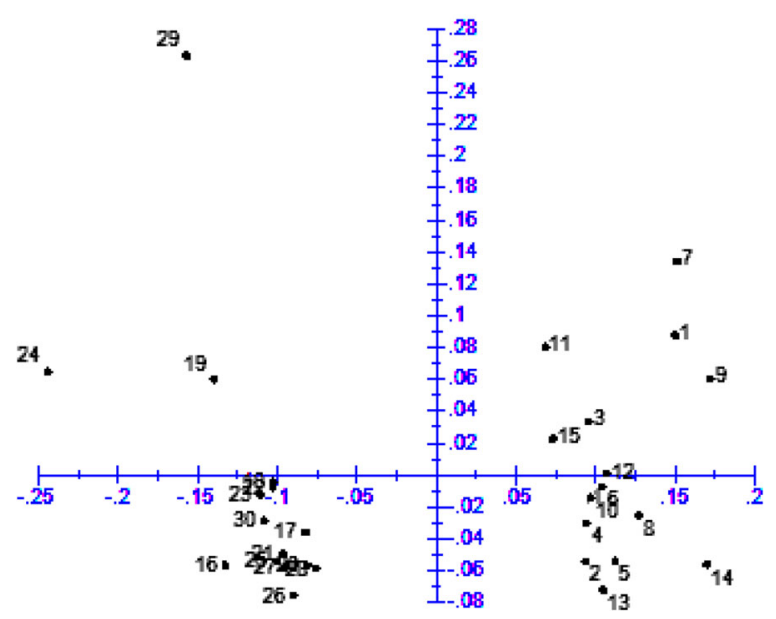

Fig. 3 Principal coordinate analysis of 30 sweet sorghum genotypes using 24 TRAP marker combinations using the dissimilarity distance matrix

resources in sweet sorghum. The results of the TRAP marker system displayed a high level of efficiency in terms of all marker attributes evaluated in comparison to other studied markers in different crops as well as in sweet sorghum. A similar result was reported with a high level of polymorphism percentage for COMT and relatively low for CAD genes on Saccharum complex comprising Miscanthus, Erianthus, Saccharum spontaneum, Saccharum robustum, and Saccharum officinarum cultivars [30]. The percentage of polymorphism for sucrose-related genes ranged between 60 (SPS) and 80\% (SuSy) which is partially in agreement with that reported in sugarcane with respect to these genes [44]. These proportions signify the fact that there is an ample amount of diversity in the test materials for the target genes. The PIC values found in the present study were ranged from 0.18 to 0.42 with lignin-related genes and from 0.22 to 0.45 with sucrose-related genes. These values were wider than those obtained in the guarana plant which ranged from 0.29 to 0.37 [28] while it was comparable to the result found in sugarcane that ranged from 0.2 to 0.4 with an average of 0.3 [32]. The PIC measures the discriminatory power of a marker system where the theoretical maximum PIC value for a dominant marker is 0.5 [34]. An average PIC value of 0.32 found in the present study is also in agreement with the value found in sweet sorghum using AFLP markers [17] and in grain sorghum using SSR markers [45]. These results depicting the fact that TRAP markers can be used as a useful tool to study genetic variability in sweet sorghum. The examined TRAP marker combinations were more effective in some parameters like resolving power than a study that compared two marker systems RAPD (PIC = $0.25, \mathrm{H}=0.4, \mathrm{PP}=94.2, \mathrm{MI}=3.94$, and $\mathrm{RP}=4.24)$ and ISSR (PIC $=0.24, \mathrm{H}=0.38, \mathrm{PP}=920, \mathrm{MI}=3.53$, and RP = 3.94) on Justicia adhatoda L. [46]. The bootstrap analysis confirmed that this marker system was able to generate a huge number of amplified fragments more than the number of loci estimated in order to precisely study genetic diversity. These results were similar to that reported on the Saccharum family which 324 markers were sufficient to explain the genetic diversity with coefficient variation of 0.5 [32], although the different techniques are used. The average gene diversity estimated by this marker system for lignin-based marker (0.374) is a relatively higher than that found for the sucrose-based markers (0.345). This finding was in contrast with that reported on

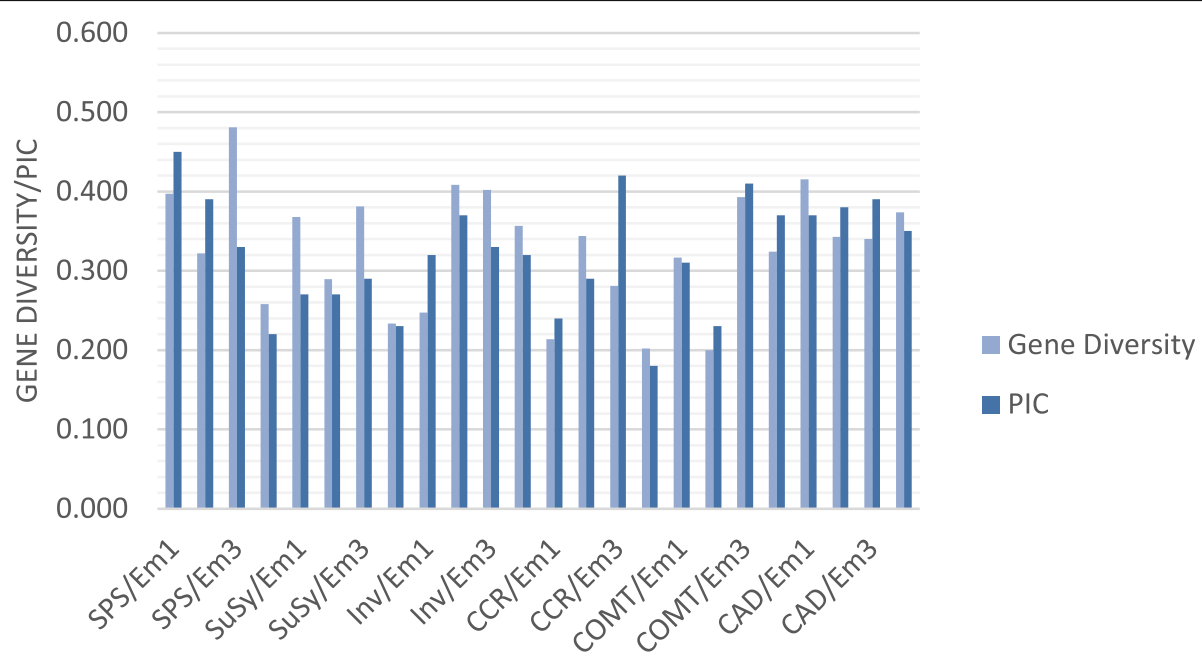

TRAP MARKER COMBINATIONS

Fig. 4 Gene diversity and polymorphic information content in 30 sweet sorghum genotypes 


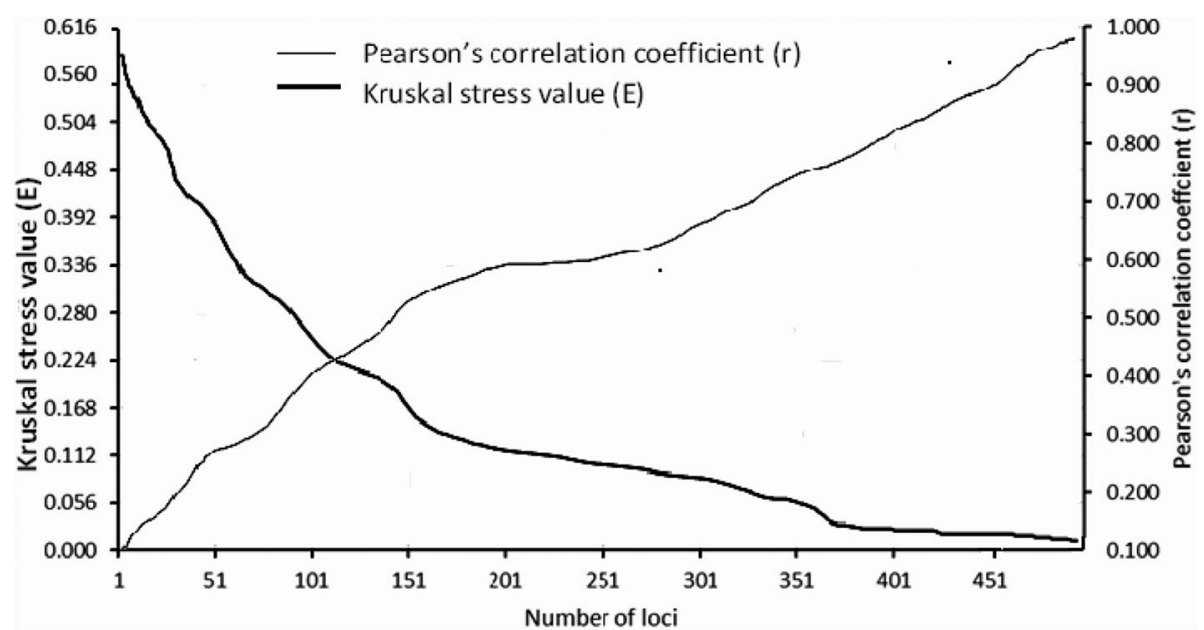

Fig. 5 Bootstrap analysis of 24 TRAP marker combinations based on Nei's genetic distance

sugarcane that represented 0.302 and 0.324 for genes involved in sugar and lignin metabolism, respectively [47]. These differences could be attributed to different numbers of primers and to the different genotypes used. Collectively, the TRAP marker combinations successfully assessed genetic variation among the 30 sweet sorghum cultivars and therefore, it could be potentially used in broadening the estimation tools of genetic diversity of this crop and in the breeding programs for developing promising cultivars with low lignin and high sugar content in the biofuel purposes (Figs. 4 and 5).

\section{Conclusions}

Exploring TRAP markers as an alternative tool for assessing genetic diversity in sorghum provides opportunity for plant breeders to select potential parents with specific traits. The evaluated TRAP marker system was effective to study genetic variation in sweet sorghum genotypes. Consequently, the TRAP marker could be used as a potential marker system in expanding the characterization of genetic variability to assist breeding programs with lignin and sucrose-related genes in improving sweet sorghum crops.

\footnotetext{
Abbreviations

PCR: Polymerase chain reaction; PIC: Polymorphic Information Content; RP: Resolving power; EMR: Effective multiplex ratio; MI: Marker index; $\mathrm{H}$ : Shannon diversity index; NCBI: National Center for Biotechnology Information; EST: Expressed sequence tag; $T_{m}$ : Melting temperature; TBE: Tris borate-EDTA; UPGMA: Unweighted pair group method with arithmetic mean; SSR: Simple sequence repeat; AFLP: Amplified Fragment Length Polymorphism; RAPD: Random Amplification of Polymorphic DNA; SNP: Single Nucleotide Polymorphism
}

\section{Acknowledgements}

The authors would like to acknowledge the University of Sadat City for providing research funds and laboratory facilities for this work. The work is a part of a PhD scholarship granted to the first author by the university through the Nile countries scholarship scheme.

\section{Authors' contributions}

YAK, AEH, and SAM conceived the study; YAK and SAM designed and performed the experiments; SAM collected data; YAK and SAM analyzed data; SAM drafted the manuscript; YAK and AEH revised the manuscript; YAK and AEH supervised the research and EA was assistant in supervising. The authors read and approved the final manuscript.

\section{Funding}

This research was funded by the University of Sadat City for providing research as a part of a PhD scholarship through the Nile countries scholarship scheme. The design of the study and collection, analysis, and interpretation of data and writing the manuscript were performed by the authors.

\section{Availability of data and materials}

Not applicable

Ethics approval and consent to participate

Not applicable

\section{Consent for publication}

Not applicable

\section{Competing interests}

The authors declare that they have no competing interests.

\section{Author details}

'Department of Plant Biotechnology, Genetic Engineering and Biotechnology Research Institute, University of Sadat City, Sadat City, Egypt.

${ }^{2}$ Department of Biology, Bahir Dar University, Bahir Dar, Ethiopia.

Received: 21 May 2020 Accepted: 8 September 2020

Published online: 06 October 2020

\section{References}

1. Rao PS, Kumar CG, Reddy BVS (2012) Sweet sorghum: from theory to practice. In: Rao PS, Kumar CG (eds) Characterization of improved sweet sorghum cultivars. Springer, Berlin, pp 1-15

2. Wortmann CS, Liska AJ, Ferguson RB, Lyon DJ, Klein RN, Dweikat I (2010) Dryland performance of sweet sorghum and grain crops for biofuel in Nebraska. Agron J 102:319-326. https://doi.org/10.2134/agronj2009.0271

3. Xu Y, Li J, Moore C, Xin Z, Wang D (2018) Physico-chemical characterization of pedigreed sorghum mutant stalks for biofuel production. Ind Crop Prod 124:806-811. https://doi.org/10.1016/j.indcrop.2018.08.049

4. Rutto LK, Xu Y, Brandt M, Ren S, Kering MK (2013) Juice, ethanol, and grain yield potential of five sweet sorghum (Sorghum bicolor [L.] Moench) cultivars. JSBS 3:113-118. https://doi.org/10.4236/jsbs.2013.32016 
5. Melillo JM, Richmond T, Yohe GW (2014) Climate change impacts in the United States: the third national climate assessment. US Global Research Program, pp 418-440

6. Balat M, Balat H, Öz C (2008) Progress in bioethanol processing. Progress Energy Combustion Sci 34:551-573. https://doi.org/10.1016/j.pecs.2007.11. 001

7. Vogel K, Bruce P, Dien S, Jung HG, Casler MD, Masterson SD, Mitchell RB (2011) Quantifying actual and theoretical ethanol yields for switchgrass strains using NIRS analyses. Bioenergy Res 4:96-110. https://doi.org/10.1007/ s12155-010-9104-4

8. Mathur S, Umakanth AV, Tonapi VA, Rita S, Sharma MK (2017) Sweet sorghum as biofuel feedstock: recent advances and available resources. Biotechnol Biofuels 10:146. https://doi.org/10.1186/s13068-017-0834-9

9. Dien BS, Sarath G, Pedersen JF, Sattler SE, Chen H, Funnell-Harris DL, Cotta MA (2009) Improved sugar conversion and ethanol yield for forage sorghum (Sorghum Bicolor L. Moench) lines with reduced lignin contents. Bioenergy Res 2:153-164. https://doi.org/10.1007/s12155-009-9041-2

10. Xue J, Yang Z, Han L, Liu Y, Liu Y, Zhou C (2015) On-line measurement of proximates and lignocellulose components of corn stover using NIRS. Appl Energy 137:18-25. https://doi.org/10.1016/j.apenergy.2014.09.089

11. Whetten RW, MacKay J, Sederoff R (1998) Recent advances in understanding lignin biosynthesis. Annu Rev Plant Physiol Plant Mol Biol 49(1):585-609. https://doi.org/10.1146/annurev.arplant.49.1.585

12. Rastogi S, Dwivedi UN (2008) Manipulation of lignin in plants with special reference to O-methyltransferase. Plant Sci 174(3):264-277. https://doi.org/ 10.1016/j.plantsci.2007.11.014

13. Sattler SE, Funnell-Harris DL, Pedersen JF (2010) Brown midrib mutations and their importance to the utilization of maize, sorghum, and pearl millet lignocellulosic tissues. Plant Sci 178(3):229-238. https://doi.org/10.1016/j. plantsci.2010.01.001

14. Tao Y, Manners JM, Ludlow MM, Henzell RG (1993) DNA polymorphisms in grain sorghum (Sorghum bicolor (L.) Moench). Theor Appl Genet 86(6):679688. https://doi.org/10.1007/BF00222656

15. Medraoui L, Ater M, Msikine OBD, Maltouf AF (2007) Evaluation of genetic variability of sorghum (Sorghum bicolor L. Moench) in northwestern Morocco by ISSR and RAPD markers. C R Biol 330(11):789-797. https://doi. org/10.1016/j.crvi.2007.08.005

16. Ritter KB, McIntyre CL, Godwin ID, Jordan DR, Chapman SC (2007) An assessment of the genetic relationship between sweet and grain sorghums, within Sorghum bicolor ssp. bicolor (L.) Moench, using AFLP markers. Euphytica 157(1-2):161-176. https://doi.org/10.1007/s10681-007-9408-4

17. Pecina-Quintero V, López JLA, Colmenero AZ, García NM, Colín CN, SolisBonilla JL, Rangel MRA, Prom L (2012) Genetic diversity of sweet sorghum germplasm in Mexico using AFLP and SSR markers. Pesq agropec bras 47(8): 1095-1102. https://doi.org/10.1590/S0100-204X2012000800009

18. Murray SC, Rooney WL, Hamblin MT, Mitchell SE, Kresovich S (2009) Sweet sorghum genetic diversity and association mapping for brix and height. Plant Genome 2(1):48-62. https://doi.org/10.3835/plantgenome2008.10.0011

19. Pei Z, Gao J, Chen Q, Wei J, Li Z, Luo F, Shi L, Sun S (2010) Genetic diversity of elite sweet sorghum genotypes assessed by SSR markers. Biologia Plantarum 54:653-658. https://doi.org/10.1007/s10535-010-0116-x

20. Wang L, Jiao S, Jiang Y, Yan H, Su D, Sun G, Yan X, Sun L (2013) Genetic diversity in parent lines of sweet sorghum based on agronomical traits and SSR markers. Field Crop Res 149:11-19. https://doi.org/10.1016/j.fcr.2013.04.013

21. Disasa T, Feyissa T, Admassu B, Paliwal R, De Villiers SM, Odeny DA (2016) Molecular evaluation of Ethiopian sweet sorghum germplasm and their contribution to regional breeding programs. AJCS 10(4):520-527. https://doi. org/10.21475/ajcs.2016.10.04.p7286x

22. Da Silva MJ, Pastina MM, de Souza VF, Schaffert RE, Carneiro PCS, Noda RW Carneiro JES, Damasceno CMB, Parrella RADC (2017) Phenotypic and molecular characterization of sweet sorghum accessions for bioenergy production. PLoS One 12(8):e0183504. https://doi.org/10.1371/journal.pone.0183504

23. Andersen JR, Lübberstedt $T$ (2003) Functional markers in plants. Trends Plant Sci 8(11):554-560. https://doi.org/10.1016/j.tplants

24. Alwala S, Suman A, Arro JA, Veremis JC, Kimbeng CA (2006) Target region amplification polymorphism (TRAP) for assessing genetic diversity in sugarcane germplasm collections. Crop Sci 46:448-455. https://doi.org/10. 2135/cropsci2005.0274

25. Hu J, Vick BA (2003) Target region amplification polymorphism: a novel marker technique for plant genotyping. Plant Mol Biol Rep 21:289-294. https://doi.org/10.1007/BF02772804
26. Poczai P, Varga I, Laos M, Cseh A, Bell N, Valkonen JPT, Hyvönen J (2013) Advances in plant gene-targeted and functional markers: a review. Plant Methods 9(1):6. https://doi.org/10.1186/1746-4811-9-6

27. Simões KS, Silva SA, Machado EL, Silva MS (2017) Genetic divergence in elite castor bean lineages based on TRAP markers. GMR 16(3):1-12. https://doi. org/10.4238/gmr16039776

28. Da Silva EF, De Sousa SB, Da Silva GF, Sousa NR, Filho FJN, Hanada RE (2016) TRAP and SRAP markers to find genetic variability in complex polyploid Paullinia Cupana Var. Sorbilis. Plant Gene 6:43-47. https:/doi.org/ 10.1016/j.plgene.2016.03.005

29. Hu J, Ochoa OE, Truco MJ, Vick BA (2005) Application of the TRAP technique to lettuce (Lactuca sativa L.) genotyping. Euphytica. 44:225-235. https://doi.org/10.1007/s10681-005-6431-1

30. Luo C, Wu HX, Yao QS, Wang SB, Xu WT (2015) Development of ESTSSR and TRAP markers from transcriptome sequencing data of the mango. Genet Mol Res 14(3):7914-7919. https://doi.org/10.4238/2015. July.14.17

31. Fabriki OS, Azarkhanian MY (2018) Genetic variability and relationships among Salvia ecotypes/species revealed by TRAP-CoRAP markers. Biotechnol Biotechnological Equip 32(6):1486-1495. https://doi.org/10.1080/ 13102818.2018 .1534555

32. Mirajkar SJ, Rai AN, Vaidya ER, Moharil MP, Dudhare MS, Suprasanna P (2017) TRAP and SRAP molecular marker based profiling of radiation induced mutants of sugarcane (Saccharum officinarum L.). Plant Gene 9:64-70. https://doi.org/10.1016/j.plgene.2017.01.002

33. Singh RB, Singh B, Singh RK (2017) Study of genetic diversity of sugarcane (Saccharum) species and commercial varieties through TRAP molecular markers. Indian J Plant Physiol 22(3):332-338. https://doi.org/10.1007/ s40502-017-0314-Z

34. Suman A, Ali K, Arro J, Parco AS, Kimbeng CA, Baisakh N (2012) Molecular diversity among members of the Saccharum complex assessed using TRAP markers based on lignin-related genes. Bioenergy Res 5:197-205. https://doi. org/10.1007/s12155-011-9123-9

35. Menzo V, Giancaspro A, Giove S, Nigro D, Zacheo S, Colasuonno P, Marcotuli I, Incerti O, Blanco A, Gadaleta A (2013) TRAP molecular markers as a system for saturation of the genetic map of durum wheat. Euphytica 194:151-160. https://doi.org/10.1007/s10681-013-0891-5

36. Prevost A, Wilkinson M (1999) A new system of comparing PCR primers applied to ISSR fingerprinting of potato cultivars. Theor Appl Genet 98:107112. https://doi.org/10.1007/s001220051046

37. Li G, Quiros CF (2001) Sequence-related amplified polymorphism (SRAP), a new marker system based on a simple PCR reaction: its application to mapping and gene tagging in Brassica. Theor Appl Genet 103:455-461. https://doi.org/10.1007/s001220100570

38. Abuzayed M, El-Dabba N, Frary A, Doganlar S (2017) GDdom: an online tool for calculation of dominant marker gene diversity. Biochem Genet 55:155157

39. Powell W, Morgante M, Andre C, Hanafey M, Vogel J, Tingey S, Rafalski A (1996) The comparison of RFLP, RAPD, AFLP and SSR markers for germplasm analysis. Mol Breeding 2:225-238. https://doi.org/10.1007/ BF00564200

40. Liu K, Muse M (2005) Power marker: an integrated analysis environment for genetic marker analysis. Bioinformatics 21:2128-2129

41. Rohlf FJ (1998) NTSYS-PC: numerical taxonomy and multivariate analysis system. Version 2.01. Exeter software, Setauket

42. Cruz CD (2013) GENES - a software package for analysis in experimental statistics and quantitative genetics. Acta Sci Agron 35:271-276

43. Kruskal JB (1964) Multidimensional scaling by optimizing goodness of fit to a no metric hypothesis. Psychometrika 29(1):1-27

44. Nasidi M, Akunna J, Deeni Y, Blackwood D, Walker G (2010) Bioethanol in Nigeria: comparative analysis of sugarcane and sweet sorghum as feedstock sources. Energ Environ Sci 3:1447-1457. https://doi.org/10.1039/c0ee00084a

45. Motlhaodi T, Mulatu G, Chite S, Fatih M, Ortiz R, Bryngelsson T (2017) Genetic diversity in sorghum [Sorghum bicolor (L.) Moench] germplasm from southern Africa as revealed by microsatellite markers and agromorphological traits. Genet Resour Crop Evol 64:599-610. https://doi.org/10. 1007/s10722-016-0388-x

46. Kumar A, Mishra P (2014) Efficiency of ISSR and RAPD markers in genetic divergence analysis and conservation management of Justicia adhatoda $\mathrm{L}$. a medicinal plant. Plant Syst Evol 300:1409-1420. https://doi.org/10.1007/ s00606-013-0970-z 
47. Junior CAD, Manechini JV, Corre^a RX, Pinto ACR, da Costa JB, Favero TM, Pinto LR (2020) Genetic structure analysis in sugarcane (Saccharum spp.) using target region amplification polymorphism (TRAP) markers based on sugar- and lignin-related genes and potential application in core collection development. Sugar Tech 22(4):641-654

\section{Publisher's Note}

Springer Nature remains neutral with regard to jurisdictional claims in published maps and institutional affiliations.

Submit your manuscript to a SpringerOpen ${ }^{\circ}$ journal and benefit from:

- Convenient online submission

- Rigorous peer review

- Open access: articles freely available online

High visibility within the field

- Retaining the copyright to your article

Submit your next manuscript at $\boldsymbol{\nabla}$ springeropen.com 